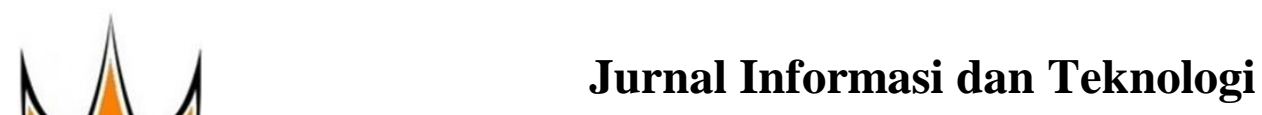

http://www.jidt.org

2021 Vol. 3 No. $3 \quad$ Hal: 95-102 ISSN: 2714-9730 (electronic)

\title{
Akurasi dalam Mengidentifikasi Citra Anggrek Menggunakan Backpropagation Artificial Neural Network
}

\author{
Ardia Ovidius $^{1 \bowtie}$, Gunadi Widi Nurcahyo ${ }^{2}$, Sumijan $^{3}$, Roni Salambue ${ }^{4}$ \\ ${ }^{1,2,3}$ Universitas Putra Indonesia YPTK Padang \\ ${ }^{4}$ Universitas Riau \\ ardia.ovidius@gmai1.com
}

\begin{abstract}
Orchids are ornamental flower plants in the Family Orchidaceae whose habitat is spread over almost all continents in the world, except Antarctica. There are so many orchid enthusiasts in Indonesia and this fact made orchids as a promising commodity for ornamental plant cultivator. With a variety of orchid species that reach more than 25,000 species, the identification of orchid species becomes a little complicated for orchid lovers. The purpose of this study was to determine the accuracy level of orchid species identification through image recognition, so that it can be used as a reference in determining the feasibility of this method. This study used 120 images of orchids in 6 species. The image of the orchid was obtained by shooting at several locations using the camera. The photo is then processed using image processing software by cropping and resizing to speed up computing time during network training. Furthermore, the MatLab software is used to perform the feature extraction process in the form of color feature data and moment invariants. Data from feature extraction is used as input for training artificial neural networks using the Back Propagation method. Calculation of the level of accuracy done by testing the network using the test data that has been provided.The trial results show that 26 of 30 were successfully recognized so that the accuracy rate can be calculated, namely $86.7 \%$. An accuracy rate of $86.7 \%$ can be considered feasible and can be used as a basis for consideration of using this tested method as the right method for identifying orchids through images.
\end{abstract}

Keywords: Accuracy, Identification, Orchidaceae, BPNN, Image Processing.

\begin{abstract}
Abstrak
Anggrek merupakan tanaman bunga hias dalam Family Orchidaceae yang habitatnya terdistribusi pada hampir seluruh benua didunia, kecuali benua Antartika.Banyaknya peminat anggrek di Indonesia menjadikan bunga ini sebagai komoditas yang cukup menjanjikan bagi penggiat tanaman hias. Dengan ragam jenis anggrek yang mencapai lebih dari 25.000 spesies, identifikasi jenis anggrek menjadi sedikit rumit bagi para pecinta anggrek. Tujuan penelitian ini adalah untuk menentukan tingkat akurasi dalam mengidentifikasi jenis anggrek melalui pengenalan gambar, sehingga dapat menjadi acuan dalam menentukan kelayakan metode tersebut. Penelitian ini menggunakan 120 citra anggrek yang terdiri dari 6 spesies. Citra anggrek tersebut diperoleh dengan melakukan pemotretan pada beberapa lokasi menggunakan kamera. Foto tersebut kemudian diolah menggunakan software pengolah citra dengan melakukan cropping dan resizing untuk mempercepat waktu komputasi saat pelatihan jaringan. Selanjutnya software MatLab digunakan untuk melakukan proses ektraksi ciri berupa data warna dan moment invariants. Data hasil ekstraksi ciri dijadikan input untuk melatih jaringan syaraf tiruan dengan metode Back Propagation. Tingkat akurasi dihitung melalui perbandingan antara jumlah citra dikenal dan yang tidak berhasil dikenali. Hasil uji coba menunjukkan bahwa 26 dari 30 berhasil dikenali sehingga tingkat akurasi dapat dihitung yaitu $86,7 \%$. Tingkat akurasi sebesar $86,7 \%$ dapat dianggap layak dan bisa dijadikan landasan pertimbangan untuk menggunakan metode yang diuji coba ini sebagai metode yang tepat dalam melakukan identifikasi anggrek melalui citra.
\end{abstract}

Kata kunci: Akurasi, Identifikasi, Anggrek, JST, Pengolahan Citra.

(C) 2021 JIdT

\section{Pendahuluan}

Anggrek merupakan tanaman dalam Family

Orchidaceae. Habitatnya terdistribusi pada hampir Selain dimanfaatkan untuk tanaman hias, tanaman seluruh benua di dunia, kecuali benua Antartika. anggrek memiliki kegunaan lain, seperti sebagai bahan Sebaran terbanyak berada pada sabuk tropis namun obat-obatan tradisional di China sampai Afrika [3]. beberapa jenis juga ditemukan di sekitar lingkaran Sebagai bahan makanan, yang paling akrab dengan kita kutub [1]. Di antara jenis tumbuhan berbunga, anggrek adalah spesies Vanilla Planifolia sebagai perisa merupakan salah satu tumbuhan dengan keluarga makanan. Bunga anggrek selain memiliki bentuk dan terbesar yang memiliki lebih dari 26.000 spesies [2], warna yang indah, species tertentu juga memiliki bau belum termasuk kemunculan jenis anggrek hibrida hasil khas yang kemudian dimanfaatkan oleh industri parfum sebagai bahan dasar bau-bauan.

Diterima: 03-03-2021 | Revisi: 14-03-2021 | Diterbitkan: 30-09-2021 | DOI: 10.37034/jidt.v3i3.115 
Di Indonesia, anggrek sangat diminati oleh pencinta Convolutional Neural Network [7], identifikasi suara tanaman hias, baik itu sebagai tanaman dekorasi dalam menggunakan JST [8], klasifikasi gambar retina ke ruangan maupun luar ruangan. Pada tahun-tahun dalam 2 kelas pada database retina [9], klasifikasi belakangan ini anggrek menjadi tanaman bunga hias Citrus Aurantifolia menggunakan metode Pattern yang paling banyak dijual dan dibudidayakan.Trend ini Recognition [10] dan analisis pengenalan tanaman dimanfaatkan oleh para petani tanaman hias untuk dalam gambar menggunakan JST [11].

menjadikan bunga anggrek sebagai komoditas yang cukup menjanjikan. Selama tahun 2018 produksi anggrek sebagai tanaman hias potong mencapai angka 24.717.840 tangkai dengan luas panen $1.767 .681 \mathrm{~m}^{2}$ [4].

Penelitian lainnya yang melibatkan BPNN adalah dalam menentukan klasifikasi 5 varietas padi melalui citra scan laser 3D [12], penentuan tingkat kematangan sawit pada 116 citra tandan buah segar [6]. Metode ini juga berhasil mengenali aksara Lontara Bugis pada foto Tumbuhan dalam keluarga Orchidaceae dapat aksara yang diambil pada manuskrip kuno Bugis [13]. digambarkan klasifikasinya mulai dari Kingdom sampai Family sebagai berikut:

\begin{tabular}{|c|l|}
\hline Kingdom & Plantae \\
\hline Subkingdom & Tracheobionta \\
\hline Superdivision & $\begin{array}{l}\text { Spermatophyta } \\
\text { Division }\end{array}$ \\
\hline Magnoliophyta \\
\hline Subclass & Liliopsida \\
\hline Order & Liliidae \\
\hline Family & $\begin{array}{l}\text { Orchidales } \\
\text { Orchidaceae } \\
749 \text { Genera, } 26000+\text { Species }\end{array}$ \\
\hline
\end{tabular}

Gambar 1. Klasifikasi Taksonomi Anggrek

Anggrek tidak bisadiidentifikasi melalui warna saja karena ciri yang lebih menonjol untuk diidentifikasi adalah bentuk, susunan dan tekstur dari bagianbagiannya [5]. Salah satu keunikan dari anggrek adalah bentuk bunganya yang simetris seperti wajah manusia (zygomorphic).Dengan beragamnya jenis anggrek, identifikasi jenis anggrek menjadi sedikit rumit bagi pehobi anggrek maupun bagi para peneliti. Pengenalan jenis anggrek secara tradisional membutuhkan pengalaman dan pengetahuan yang mendalam.Dengan perkembangan teknologi komputer dibidang pattern recognition maka masalah ini dapat diminimalisir melalui penerapan jaringan syaraf tiruan (JST) [6].

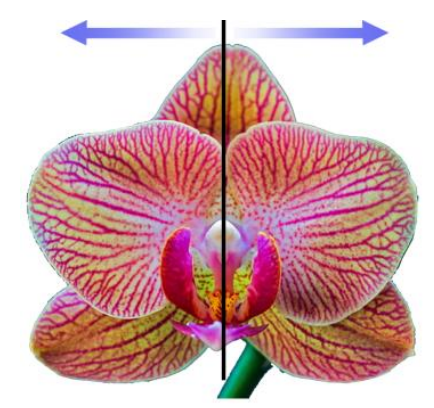

Gambar 2. Bentuk Bunga Anggrek dengan Struktur Zygomorphic

Penggunaan JST sudah umum digunakan oleh para peneliti dalam melakukan klasifikasi atau identifikasi.Metoda pembelajaran JST yang paling umum digunakan adalah Back Propagation Neural Network (BPNN). Metoda ini digunakan dalam beberapa penelitian sebelumnya seperti melakukan identifikasi 15 species anggrek menggunakan teknik
Berdasarkan latar belakang tersebut maka ditentukan rumusan permasahan yaitu: bagaimana proses ekstraksi dari citra anggrek untuk dijadikan input pada BPNN dalam melakukan pelatihan pengenalan gambardan bagaimana mengukur tingkat akurasi metode BPNN mengidentifikasi jenis anggrek dalam sebuah citra. Kinerja sistem diukur menggunakan parameter konvergensi dan generalisasi.Hasil penelitian ini diharapkan dapat menjadi pengetahuan bagi peneliti berikutnya tentang tingkat akurasi BPNN dalam mengidentifikasi anggrek dalam sebuah citra.

\section{Metodologi Penelitian}

Penelitian ini dilakukan dengan mengikuti kerangka kerja agar penelitian dilakukan dengan terstruktur dan terarah. Kerangka kerja merupakan tahapan-tahapan proses penelitan yang terurut berdasarkan langkahlangkah yang saling berkaitan seperti pada Gambar 3 .

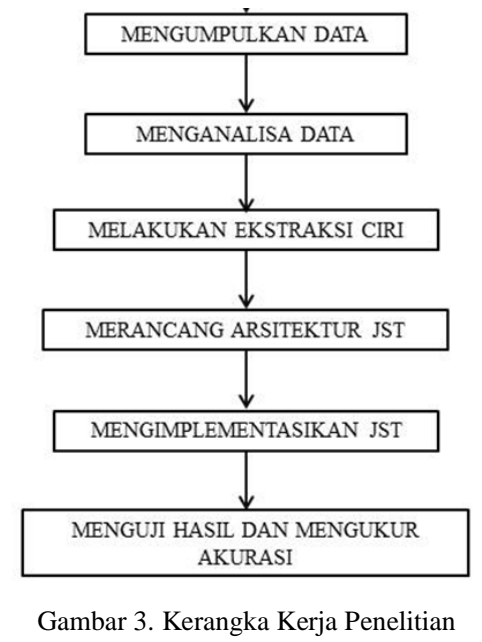

\subsection{Mengumpulkan Data}

Data yang digunakan pada penelitian ini adalah data primer yang didapat dengan melakukan akuisisi langsung.Pengumpulan data dilakukan dengan metode studi lapangan pada penjual tanaman hias yang ada di sekitar Kota Padang dan rumah-rumah masyarakat yang memiliki tanaman anggrek. Akuisisi terhadap citra digital bunga anggrek diambil menggunakan kamera smartphone. 
Jenis-jenis anggrek yang digunakan bisa dilihat pada Gambar 4 di bawah, berurutan dari kiri ke kanan Anggrek A, B, C, D, E, F:

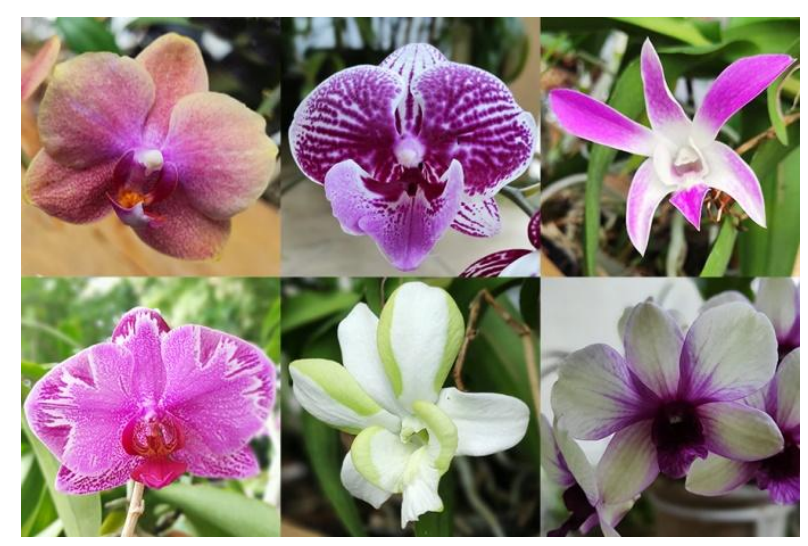

Gambar 4. Sampel Data dari 6 Spesies Anggrek

\subsection{Menganalisa Data}

Citra dianalisa untuk menentukan kelayakan sebagai sampel yang akan digunakan pada proses pelatihan jaringan. Kriteria citra yang tidak layak adalah citra yang terpotong, kabur, Over/Underexposure dan citra B/W.Kriteria ini ditampilkan pada Tabel 1.

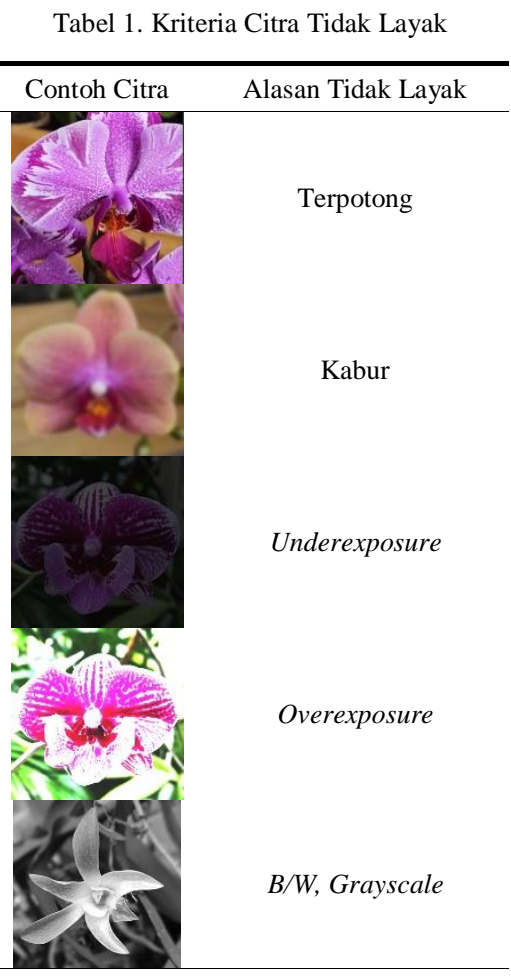

Preprocessingcitra dilakukan menggunakan aplikasi pengolah citra Photoshop. Proses awal meliputi rotasi, penskalaan, mirroring agar terbentuk sample yang variatif. Untuk mempercepat waktu pemrosesan, dilakukan cropping untuk memperkecil dimensi gambar sekaligus mengeliminasi informasi yang tidak penting dalam citra.Proses cropping dan rotasi ditampilkan pada Gambar 5 dan Gambar 6.

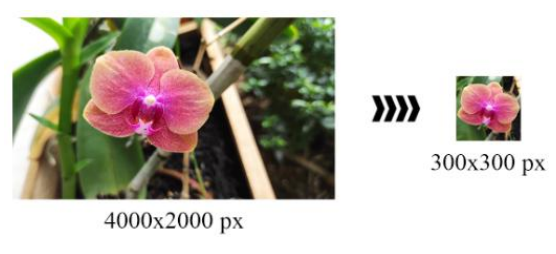

Gambar 5. Proses Cropping

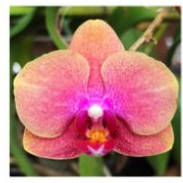

Original

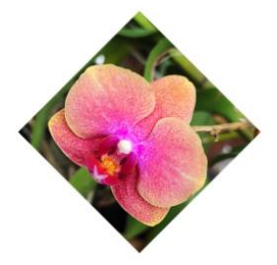

Rotasi $45^{\circ}$

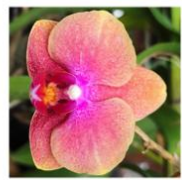

Rotasi $90^{\circ}$
Gambar 6. Proses Rotasi

Sampel data untuk pelatihan jaringan terdiri dari 6 spesies anggrek dengan total sebanyak 120 gambar.Gambar tersebut termasuk hasil proses rotasi dari gambar awal, kemudian 30 gambar di antaranya dijadikan data uji.Tabel 2 menyajikan properti komposisi citra.

Tabel 2. Komposisi Citra Sampel

\begin{tabular}{cll}
\hline No. & \multicolumn{1}{c}{ Keterangan } & \multicolumn{1}{c}{ Nilai } \\
\hline 1. & Jumlah Citra Sampel Pelatihan & 90 \\
2. & Jumlah Citra Uji & 30 \\
3. & Format & JPG \\
4. & Variasi Orientasi & Kelipatan $45^{\circ}$ \\
5. & Dimensi Citra & $300 \times 300 \mathrm{px}$ \\
6. & Mode Warna & RGB \\
\hline
\end{tabular}

\subsection{Melakukan Ekstraksi Ciri}

Dalam proses pengenalan gambar dibutuhkan data ciriciri dari objek yang akan dikenali sebagai pembeda antar objek. Namun sebelumnya harus melewati tiga tahapan proses seperti pengolahan gambar, ekstraksi ciri baru kemudian dilakukan klasifikasi [11].

\subsubsection{Ciri Warna}

Nilai yang paling umum digunakan dalam sebuah pengenalan gambar ciri warna karena tidak terpengaruh oleh orientasi gambar, perputaran maupun arah dan ukuran. Warna pada sebuah citra merupakan kombinasi dari tiga warna utama yaitu biru, merah dan hijau atau biasa disebut dengan RGB yang akan membentuk sebuah warna komposit [14], di mana warna-warna primer ini didasarkan pada sistem koordinat kartesian 3-D berbentuk kubus seperti pada Gambar 7.

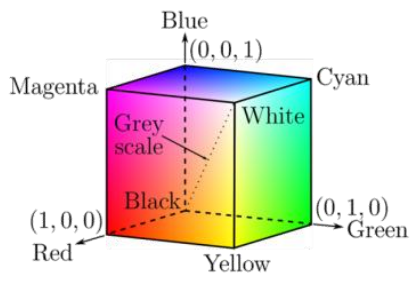

Gambar 7. Sistem Warna RGB 
Nilai ciri dari tiap unsur warna dilakukan melalui 2.3.2. Ciri Bentuk normalisasi masing-masing unsur dengan persamaan di bawah ini:

$$
\begin{aligned}
r & =\frac{M}{M+H+B} \\
g & =\frac{H}{M+H+B} \\
b & =\frac{B}{M+H+B}
\end{aligned}
$$

di mana $\mathrm{M}$ adalah merah, $\mathrm{H}$ adalah hijau dan $\mathrm{B}$ adalah biru. Model RGB sangat ideal untuk menghasilkan warna pada citra berwarna seperti pada gambar hasil foto atau pada layar monitor, tapi sebagai keterangan warna (color descriptor) penggunaannya sangat terbatas sekali. Oleh karena itu untuk memperoleh tingkat kecerahan warna model RGB harus dikonversi kedalam model warna hue, saturation, intensity/value (HSI/HSV).

Hue adalah atribut warna yang menjelaskan warna murninya (seperti merah, biru, orange, dan lain lain), Saturation menggambarkan derajat warna murni tersebut tercampur dengan warna putih, sementara Intensity/Value adalah deskripsi tingkat sensasi cahaya [15]. Model warna HSV/HIS dapat dilihat pada Gambar 8 .
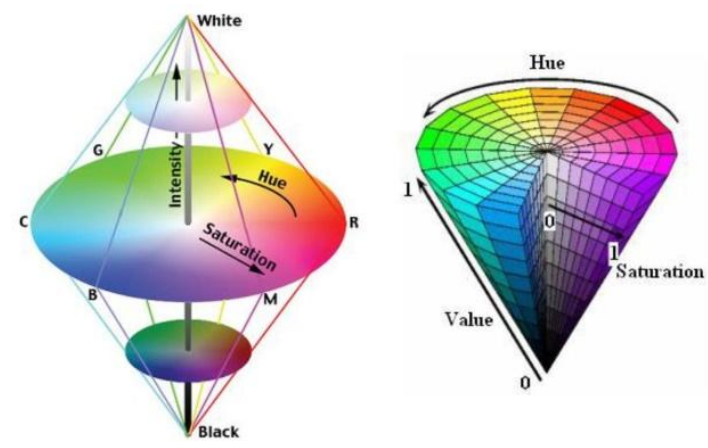

Gambar 8. Sistem Warna HSV/HSI

Untuk mendapatkan nilai Hue pada gambar RGB bisa menggunakan persamaan berikut ini:

$$
\text { Hue }= \begin{cases}\theta & \text { jika } B \leq H \\ 360-\theta & \text { jika } B>H\end{cases}
$$

di mana,

$$
\theta=\cos ^{-1}\left\{\frac{\frac{1}{2}[(M-H)+(M-B)]}{\left[(M-H)^{2}+(M-B)(H-B)\right]^{\frac{1}{2}}}\right\}(5)
$$

Nilai komponen Saturation diperoleh melalui persamaan:

$$
S=1-\frac{3}{(M+H+B)}[\min (M, H, B)]
$$

Sementara nilai Intensity dapat dihasilkan melalui perhitungan:

$$
I=\frac{1}{3}(M+H+B)
$$

Dalam proses object recognition, deskripsi bentuk adalah properti yang paling mendasar pada objek tersebut. Hu pada tahun 1962 memperkenalkan sebuah metode yang sangat populer dalam mendeskripsikan bentuk berdasarkan kontur yaitu momen invarian [16]. Dalam penelitian ini momen invarian akan dihitung dari citra skala abu-abu seperti pada Gambar 9 untuk membangun deskripsi bentuk ke dalam himpunan vektor momen invarian.

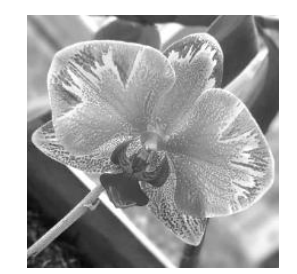

Gambar 9. Citra Skala Abu-abu

Satu set momen invarian 2-D yang terdiri dari tujuh persamaan, di mana momen invarian ini konsisten terhadap perputaran, pergeseran dan perobahan ukuran gambar dapat diformulasikan sebagai berikut:

1. $\phi_{1}=\tilde{n}_{20}+\tilde{n}_{02}$

2. $\phi_{2}=\left(\tilde{\mathrm{n}}_{20}-\tilde{\mathrm{n}}_{02}\right)^{2}+4 \tilde{\mathrm{n}}_{11}^{2}$

3. $\phi_{3}=\left(\tilde{\mathrm{n}}_{30}-3 \tilde{\mathrm{n}}_{12}\right)^{2}+\left(3 \tilde{\mathrm{n}}_{21}-\tilde{\mathrm{n}}_{03}\right)^{2}$

4. $\phi_{4}=\left(\tilde{\mathrm{n}}_{30}+\tilde{\mathrm{n}}_{12}\right)^{2}+\left(\tilde{\mathrm{n}}_{21}+\tilde{\mathrm{n}}_{03}\right)^{2}$

5. $\phi_{5}=\left(\tilde{\mathrm{n}}_{30}-3 \tilde{\mathrm{n}}_{12}\right)\left(\tilde{\mathrm{n}}_{30}+\tilde{\mathrm{n}}_{12}\right)\left[\left(\tilde{\mathrm{n}}_{30}+\tilde{\mathrm{n}}_{12}\right)^{2}-\right.$ $3 \tilde{n} 21+\tilde{n} 032+(3 \tilde{n} 21-\tilde{n} 03)(\tilde{n} 21+\tilde{n} 03) 3 \tilde{n} 30+\tilde{n} 12$ $2-(\tilde{n} 21+\tilde{n} 03) 2$

6. $\phi_{6}=\left(\tilde{\mathrm{n}}_{20}-\tilde{\mathrm{n}}_{02}\right)\left[\left(\tilde{\mathrm{n}}_{30}+\tilde{\mathrm{n}}_{12}\right)^{2}-\left(\tilde{\mathrm{n}}_{21}+\tilde{\mathrm{n}}_{03}\right)^{2}\right]+$ $4 \tilde{\mathrm{n}}_{11}\left(\tilde{\mathrm{n}}_{30}+\tilde{\mathrm{n}}_{12}\right)\left(\tilde{\mathrm{n}}_{21}+\tilde{\mathrm{n}}_{03}\right)$

7. $\phi_{5}=\left(3 \tilde{n}_{21}-\tilde{n}_{03}\right)\left(\tilde{n}_{30}+\tilde{n}_{12}\right)\left[\left(\tilde{n}_{30}+\tilde{n}_{12}\right)^{2}-\right.$ $3 \tilde{n} 21+\tilde{n} 032+(3 \tilde{n} 12-\tilde{n} 30)(\tilde{n} 21+\tilde{n} 03) 3 \tilde{n} 30+\tilde{n} 12$ $2-(\tilde{n} 21+\tilde{n} 03) 2(8)$

di mana:

$\phi=$ momen invarian

$\tilde{\mathrm{n}}=$ momen pusat yang sudah dinormalisasi

Nilai yang akan digunakan sebagai input BPNN adalah hasil ekstraksi ciri dari citra yang berupa nilai warna (RGB, HSV) dan nilai momen invarian. Jumlah input yang akan diolah adalah sebanyak 13 input yang terdiri dari 3 nilai RGB, 3 nilai HSV dan 7 nilai momen invarian seperti yang tersaji pada Tabel 3. 
Ardia Ovidius, Gunadi Widi Nurcahyo, Sumijan, Roni Salambue.

\begin{tabular}{lcl}
\multicolumn{3}{c}{ Tabel 3. Variabel Hasil Ekstraksi Ciri } \\
\hline Variabel & Ciri & \multicolumn{1}{c}{ Jenis Ciri } \\
\hline F1 & Red & Warna (Merah) \\
F2 & Green & Warna (Hijau) \\
F3 & Blue & Warna (Biru) \\
F4 & Hue & Warna (Hue) \\
F5 & Saturation & Warna (Saturasi) \\
F6 & Intensity & Warna (Intensitas) \\
F7 & $\phi 1$ & Invariant Moment \\
F8 & $\phi 2$ & Invariant Moment \\
F9 & $\phi 3$ & Invariant Moment \\
F10 & $\phi 4$ & Invariant Moment \\
F11 & $\phi 5$ & Invariant Moment \\
F12 & $\phi 6$ & Invariant Moment \\
F13 & $\phi 7$ & Invariant Moment \\
\hline
\end{tabular}

\subsection{Merancang Arsitektur JST}

JST bekerja dengan meniru cara kerja otak manusia, di mana JST juga memiliki jaringan-jaringan dengan elemen pemrosesan yang saling terhubung.Jaringan otak manusia mampu melakukan pengenalan objek dengan menyimpan pengetahuan dalam komponen berupa synapse, neuron dan komponen lainnya.JST menyimpan pengetahuan yang didapat melalui pelatihan ke dalam bentuk nilai bobot sambungan antar neuron (synapse otak manusia direpresentasikan menjadi bobot/weight pada JST) dan elemen komputasi.

BPNN adalah model JST dengan arsitektur multi layer perceptronyang sering digunakan untuk melakukan pengenalan pola (pattern recognition). Karakteristik BPNN sebagai berikut:

\section{a. Jaringan Multilayer}

Lapisan input, lapisan tersembunyi dan lapisan output adalah komponen yang membentuk BPNN. Masing-masing neuron pada tiap lapisan memperoleh input dari tiap neuron yang ada pada lapisan sebelumnya. Arsitektur multilayer diilustrasikan pada Gambar 10.

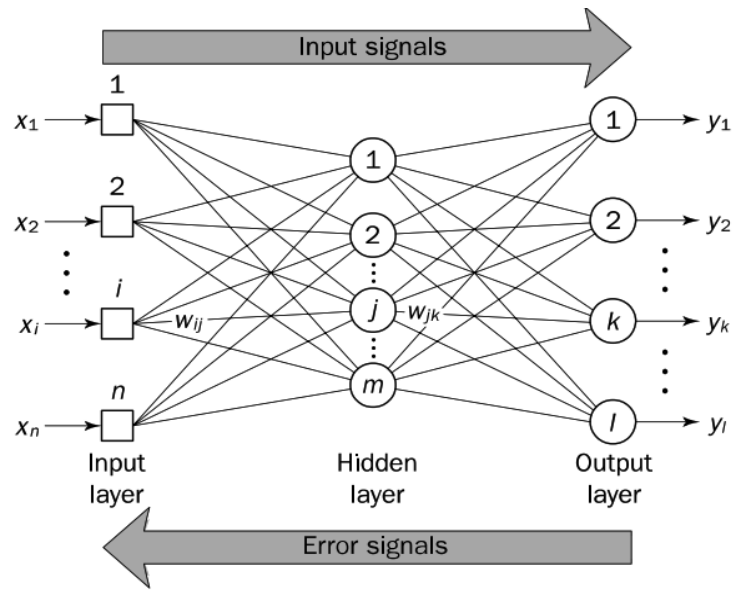

Gambar 10. Arsitekur JST Propagasi Balik

\section{b. Fungsi Aktivasi}

JST menentukan nilai output dengan cara menghitung nilai input yang sudah diberi bobot dan Setelah melakukan proses awal pada data sampel maka kemudian dibandingkan dengan nilai proses selanjutnya adalah ekstraksi terhadap 13 ciri ambang/treshold (disebut dengan fungsi aktifasi). yang merupakan nilai input untuk BPNN. Total waktu
Beberapa fungsi aktifasi yang populer digunakan dapat dilihat pada Gambar 11 berikut:

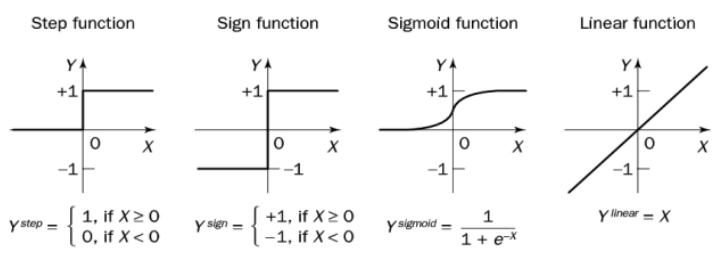

Gambar 11. Fungsi Aktifasi pada Neuron

Sigmoid Function mentransformasi masukan pada JST yang bisa saja memiliki nilai di antara nilai positif dan minus tak berhingga menjadi nilai output dalam rentang 0 sampai dengan 1. Neuron dengan fungsi sigmoid digunakan pada JST bertype Back Propagation.

Untuk mencapai nilai bobot dan bias optimal pada masing-masing lapisan JST, pelatihan ini dilakukan berulang sampai nilai error mencapaiambang yang bisa ditoleransi.

Perancangan BPNN pada penelitian ini disesuaikan dengan paremeter input dan output yaitu 13 simpul masukan dan 6 simpul keluaran.

\subsection{Mengimplementasikan BPNN}

Arsitektur BPNN dalam penelitian ini dapat dilihat pada Gambar 12 berikut ini:

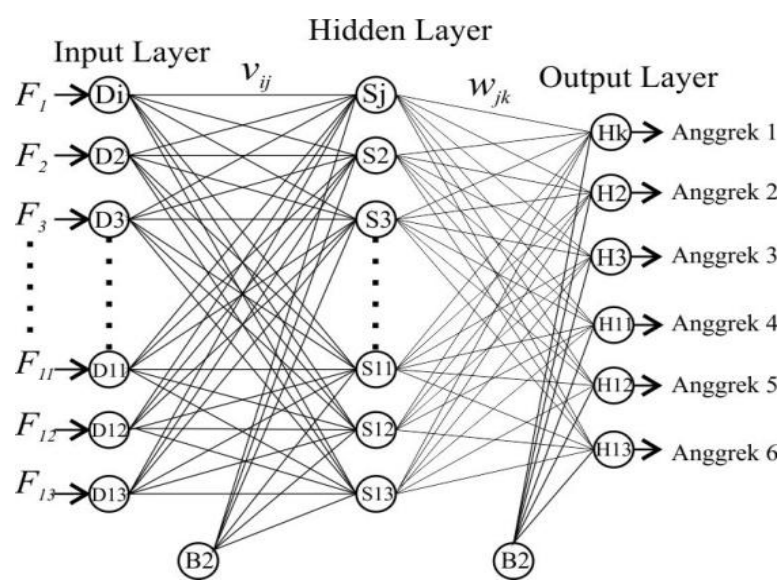

Gambar 12. Arsitektur BPNN Multi Layer

\section{Hasil dan Pembahasan}

Aktifitas dalam penelitian ini terdiri dari tiga tahap yaitu proses ekstraksi ciri, pelatihan BPNN dan pengujian BPNN. Input yang diberikan kepada jaringan terdiri dari ciri warna dan bentuk. Jumlah citra sampel berjumlah 120yang berasal dari6 spesies.Sampel dibagi menjadi dua bagian,90 citra digunakan untuk pelatihan dan 30 citra untuk pengujian.

\subsection{Ekstraksi Ciri}

\section{c. Fungsi Training berulang (iterative)}


yang dikonsumsi untuk melakukan ekstraksi ciri dari Langkah 3 : Pelatihan Bobot

120 citra adalah 6.5 detik.Contoh hasil ekstraksi ciri untuk tiap-tiap jenis dapat dilihat pada Tabel 4 berikut, di mana variabel F1-F3 adalah nilai $R, G, B$ diikuti F4F6 adalah nilai untuk $\mathrm{H}, \mathrm{S}, \mathrm{V}$ dan variabel $\mathrm{F} 7-\mathrm{F} 13$ adalah nilai 7 momen invarian.

Tabel 4. Contoh Nilai Hasil Ekstraksi Ciri

\begin{tabular}{lcrrrrr}
\hline Var & $\begin{array}{c}\text { Anggrek } \\
\mathrm{A}\end{array}$ & $\begin{array}{c}\text { Anggrek } \\
\mathrm{B}\end{array}$ & $\begin{array}{c}\text { Anggrek } \\
\mathrm{C}\end{array}$ & $\begin{array}{c}\text { Anggrek } \\
\mathrm{D}\end{array}$ & $\begin{array}{c}\text { Anggrek } \\
\mathrm{E}\end{array}$ & $\begin{array}{c}\text { Anggrek } \\
\mathrm{F}\end{array}$ \\
\hline $\mathrm{F}_{1}$ & 163.03 & 137.30 & 112.93 & 152.24 & 135.0775 & 128.2870 \\
$\mathrm{~F}_{2}$ & 105.87 & 96.30 & 102.57 & 116.07 & 141.7101 & 117.7877 \\
$\mathrm{~F}_{3}$ & 100.15 & 133.34 & 97.4630 & 122.43 & 109.8967 & 121.1071 \\
$\mathrm{~F}_{4}$ & 0.4343 & 0.5764 & 0.32654 & 0.5139 & 0.236785 & 0.466698 \\
$\mathrm{~F}_{5}$ & 0.4839 & 0.4271 & 0.37117 & 0.5386 & 0.307033 & 0.260908 \\
$\mathrm{~F}_{6}$ & 0.6468 & 0.5823 & 0.4793 & 0.6518 & 0.565241 & 0.518283 \\
$\mathrm{~F}_{7}$ & 0.0013 & 0.0014 & 0.0013 & 0.0012 & 0.000995 & 0.001393 \\
$\mathrm{~F}_{8}$ & $9.6 \mathrm{e}-09$ & $1.28 \mathrm{e}-09$ & $3.4 \mathrm{e}-10$ & $1.85 \mathrm{e}-10$ & $7.75 \mathrm{e}-09$ & $7.04 \mathrm{e}-09$ \\
$\mathrm{~F}_{9}$ & $4.2 \mathrm{e}-12$ & $6.75 \mathrm{e}-11$ & $8.7 \mathrm{e}-12$ & $1.61 \mathrm{e}-11$ & $2.07 \mathrm{e}-12$ & $1.65 \mathrm{e}-11$ \\
$\mathrm{~F}_{10}$ & $1.3 \mathrm{e}-11$ & $5.01 \mathrm{e}-12$ & $1.2 \mathrm{e}-11$ & $7.29 \mathrm{e}-12$ & $1.44 \mathrm{e}-12$ & $5.68 \mathrm{e}-11$ \\
$\mathrm{~F}_{11}$ & $5.6 \mathrm{e}-23$ & $8.65 \mathrm{e}-23$ & $2.0 \mathrm{e}-23$ & $-4.2 \mathrm{e}-23$ & $1.76 \mathrm{e}-24$ & $9.25 \mathrm{e}-22$ \\
$\mathrm{~F}_{12}$ & $-3.8 \mathrm{e}-16$ & $-9.9 \mathrm{e}-17$ & $-7.2 \mathrm{e}-17$ & $-9.0 \mathrm{e}-17$ & $-1.0 \mathrm{e}-17$ & $-3.2 \mathrm{e}-15$ \\
$\mathrm{~F}_{13}$ & $-8.12 \mathrm{e}-23$ & $-3.1 \mathrm{e}-23$ & $-1.3 \mathrm{e}-22$ & $-6.6 \mathrm{e}-23$ & $-1.7 \mathrm{e}-24$ & $1.48 \mathrm{e}-21$ \\
\hline & & & & & & \\
\hline
\end{tabular}

\subsection{Pelatihan BPNN}

Jaringan syaraf tiruan dibangun menggunakan software MatLab sesuai dengan rancangan arsitektur yang telah dijabarkan pada Bagian 2.5. Arsitektur jaringan yang terbentuk pada software MatLab diilustrasikan pada Gambar 13.

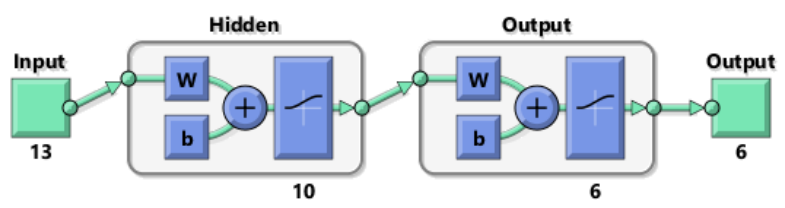

Gambar 13. Ilustrasi Arsitektur BPNN pada MatLab

Inisialisasi bobot dan bias masing-masing lapisan dilakukan secara acak oleh sistem pada saat JST dibentuk.

Algoritma dari pembelajaran BPNN adalah sebagai berikut:

\section{Langkah 1 :Inisialisasi}

Tentukan bobot dan bias $(\beta)$ awal secara acak dalam range yang cukup kecil. Di samping itu, tetapkan juga batas epoch maksimal, batas tingkat error dan laju pembelajaran/learning rate $(\alpha)$, nilai masingmasing input layer dan nilai target.

Langkah 2 :Aktivasi

Aktifkan jaringan dengan memasukkan nilai input $F_{1}, F_{2}, \ldots F_{n}$ dan nilai target output $D_{t .1}, D_{t .2}, \ldots, D_{t . n}$.

a. Hitung nilai keluaran dari masing-masing simpul pada lapisan tersembunyi pada pengulangan ke $u$ : $S_{j}(u)=\operatorname{sigmoid}\left[\sum_{i=1}^{n} F_{i}(u) \times v_{i j}(u)-b_{1}\right](9)$ di mana $n$ adalah jumlah input pada simpulS.

b. Hitung nilai keluaran aktual dari masing-masing simpul lapisan output:

$H_{k}(u)=\operatorname{sigmoid}\left[\sum_{j=1}^{m} S_{j}(u) \times w_{j k}(u)-b_{2}\right](10)$ di mana $m$ adalah jumlah input pada simpul $D$.
Perbaharui nilai bobot dengan mengirim balik nilai kesalahan pada masing-masing simpul keluaran.

a. Hitung nilai error gradient untuk simpul pada lapisan keluaran:

$$
\mathrm{e}_{k}(u)=H_{k}(u) \times\left[1-H_{k}(u)\right] \times e_{k}(u)
$$

di mana

$$
e_{k}(u)=H_{t . k}-H_{k}(u)
$$

Berikutnya hitung besaran koreksi nilai bobot:

$$
\Delta w_{j k}(u)=\alpha \times S_{j}(u) \times \mathrm{e}_{k}(u)(13)
$$

Perbarui nilai bobot pada lapisan keluaran:

$$
w_{j k}(u+1)=w_{j k}(u)+\Delta w_{j k}(u)
$$

b. Hitung nilai error gradient untuk simpul pada lapisan tersembunyi:

$\mathrm{e}_{j}(u)=S_{j}(u) \times\left[1-S_{j}(u)\right] \times \sum_{k=1}^{l} \mathrm{e}_{k}(u) \times w_{j k}(u)$

Berikutnya hitung besaran koreksi nilai bobot:

$$
\Delta v_{i j}(u)=\alpha \times F_{i}(u) \times \mathrm{e}_{j}(u)
$$

Perbarui nilai bobot pada lapisan tersembunyi:

$$
v_{i j}(u+1)=v_{i j}(u)+\Delta v_{i j}(u)
$$

Langkah 4 : Pengulangan

Lakukan perulangan $u$ satu per satu dan ulang proses Langkah 2 \& Langkah 3 sampai ambang batas kriteria error terpenuhi.

\subsection{Implementasi BPNN}

JST yang sudah dirancang kemudian dibangun modelnya pada aplikasi MatLab. Model jaringan dibentuk dengan parameter seperti yang dipaparkan pada Tabel 5 sebagai berikut:

Tabel 5. Struktur JST Identifikasi Anggrek dalam Citra

\begin{tabular}{ll}
\hline KARAKTERISTIK & SPESIFIKASI \\
\hline Arsitektur & Multilayer, 1 hidden \\
Neuron input & 13 \\
Neuronhidden & 10 \\
Neuron output & 6 \\
Transfer Function & Logsig \\
Fungsi pembelajaran & Trainlm \\
Penilaian kinerja & Mse \\
Toleransi error & 0.0001 \\
Laju pembelajaran & 0.01 \\
Jumlah iterasi maksimum & 3000 epochs \\
\hline
\end{tabular}

Pelatihan dengan performa terbaik dihasilkan menggunakan 90 data sampel diselesaikan dalam 44 kali iterasi dalam waktu 0.871115 detik. Nilai mean square error terendah berada pada posisi $8.6203 \mathrm{e}-05$, terlihat pada Gambar 14. 


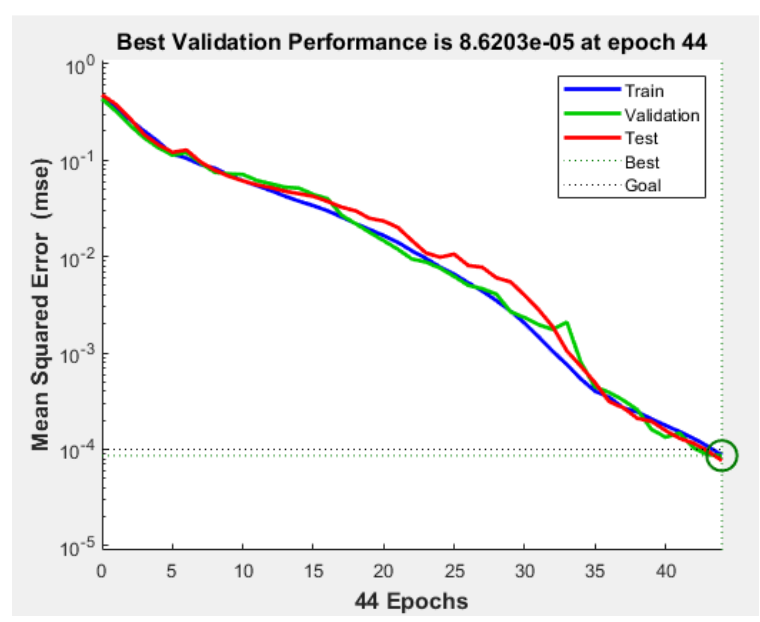

Gambar 14. Grafik Nilai MSE Selama Pelatihan JST

JST yang sudah dilatih kemudian diuji kemampuannya untuk mengenali seluruh data yang digunakan untuk pelatihan maka hasil identifikasi dapat dilihat pada confusion matrix pada Gambar 15 berikut ini:

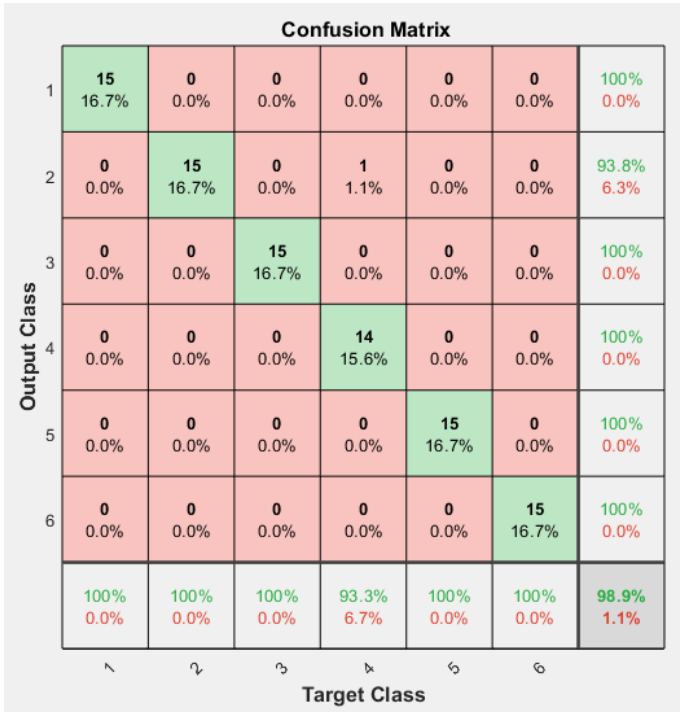

Gambar 15. Matrix Pengujian dengan Data Training

Terlihat pada matriks di atas bahwa JST berhasil mengenali $100 \%$ untuk anggrek jenis A, B, C, E dan F. Sementara untuk anggrek jenis $\mathrm{D}$ hanya bisa dikenali 93\%. Tingkat akurasi dengan data training adalah $98,9 \%$.

Berikutnya JST diuji kemampuannya untuk mengenali 30 citra baru, hasil pengujian dapat dilihat pada confusion matrix pada Gambar 16.

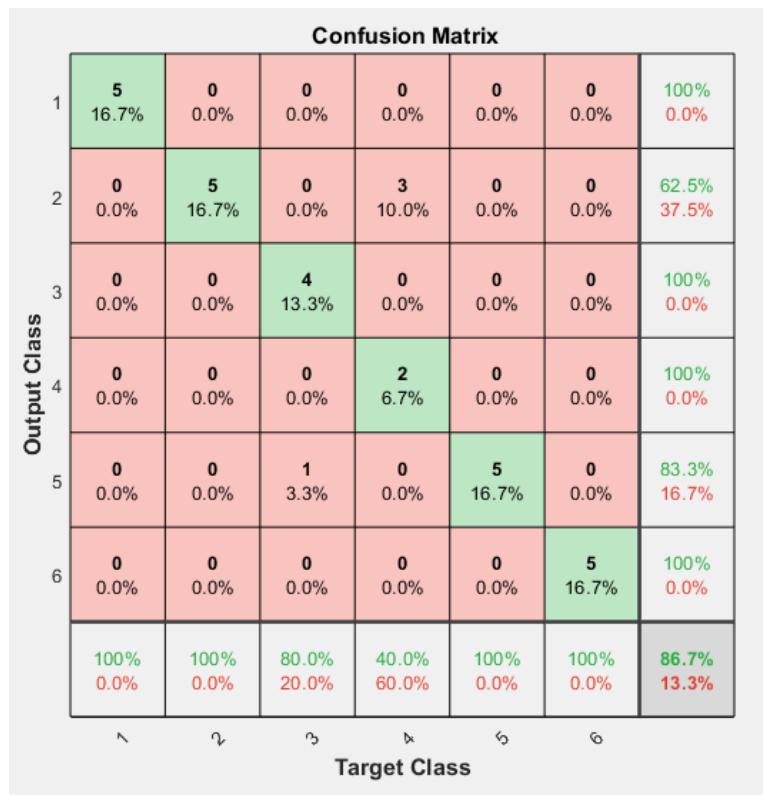

Gambar 16. Matrix Pengujian Dengan 30 Data Baru

Terlihat pada matriks di atas bahwa JST berhasil mengenali 100\% untuk anggrek jenis A, B, E dan F. Sementara untuk anggrek jenis $\mathrm{C}$ dan $\mathrm{D}$ masingmasingnya hanya bisa dikenali $80 \%$ dan $40 \%$. Tingkat akurasi JST adalah sebesar 86,7\%.

Tingkat pengenalan yang paling rendah adalah pada anggrek jenis D yang lebih banyak dikenali sebagai anggrek jenis B. Hal ini kemungkinan disebabkan oleh bentuk yang sangat mirip dan warna yang hampir sama, seperti terlihat pada Gambar 17.

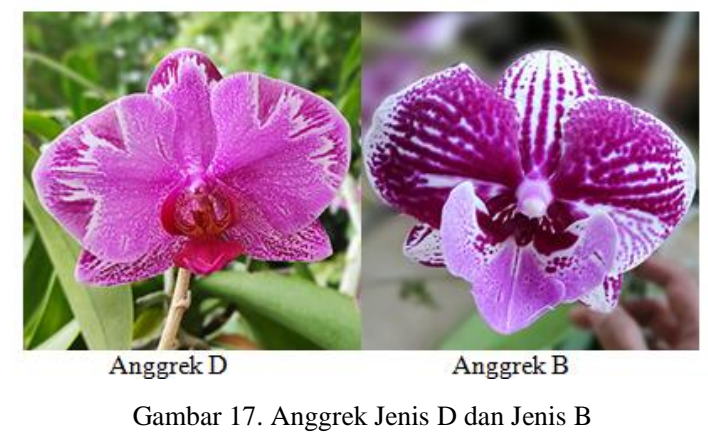

\section{Kesimpulan}

Berangkat dari hasil pengujian tersebut tingkat akurasi identifikasi anggrek dalam citra adalah 86,7\% untuk sampel citra baru yaitu 26 dari 30 citra, sementara dari 90 sampel citra yang sudah dikenalkan pada jaringan berhasil dikenali sebanyak 89 gambar dengan akurasi 98,9\%. Tingkat akurasi sebesar 86,7\% dapat dianggap layak dan bisa dijadikan landasan pertimbangan untuk menggunakan metode yang diuji coba ini sebagai metode yang tepat dalam melakukan identifikasi anggrek melalui citra.

Ketidak akuratan identifikasi pada salah satu jenis anggrek disebabkan karena bentuk dan warna yang saling mendekati. Kemiripan ini sangat umum dijumpai pada hampir seluruh jenis anggrek sehingga harus ada 
ciri pembeda lain yang harus diikutkan sebagai input [9] Arasy, R., \& Basari. (2019). Detection Of Hypertensive pelatihan JST.

\section{Daftar Rujukan}

[1] Wikipedia (2020), Orchidaceae, (Updated 11 October 2020) available at https://en.wikipedia.org/wiki/Orchidaceae [Accessed 25 October 2020].

[2] Chase, M., Christenhusz, M. \& Mirenda, T (2017), The Book of Orchids. Brighton, UK: The Ivy Press Limited.

[3] Teoh, E. S. (2019). Medicinal Orchid Usage in Rural Africa. Orchids as Aphrodisiac, Medicine or Food, 305-362. DOI: http://doi.org/10.1007/978-3-030-18255-7_17 .

[4] BPS Indonesia (2020), Statistik Indonesia (Statistical Yearbook of Indonesia) 2019, Jakarta: Badan Pusat Statistik Indonesia.

[5] Meisel, J. E., Kaufmann, R. S., \& Pupulin, F. (2015). Orchids of Tropical America. New York, USA. Cornell University Press. DOI: http://doi.org/10.7591/9780801454929-005 .

[6] Minarni, M., Salumbae, R., \& Hasbi, Z. (2018). Implementasi Jaringan Syaraf Tiruan (JST) dan Pengolahan Citra Untuk Klasifikasi Kematangan TBS Kelapa Sawit. Komunikasi Fisika Indonesia, 15(1), 36. DOI: http://doi.org/10.31258/jkfi.15.1.3645 .

[7] Arwatchananukul, S., Kirimasthong, K., \& Aunsri, N. (2020). A New Paphiopedilum Orchid Database and Its Recognition Using Convolutional Neural Network. Wireless Personal Communications, 155. DOI: http://doi.org/10.1007/s11277-02007463-3.

[8] Devi, K. J., Devi, A. A., \& Thongam, K. (2019). Automatic Speaker Recognition using MFCC and Artificial Neural Network. International Journal of Innovative Technology and Exploring Engineering, 9(1S), 39-42. DOI: http://doi.org/10.35940/ijitee.a1010.1191s19. Retinopathy Using Principal Component Analysis (PCA) and Backpropagation Neural Network Methods. AIP Conference Proceedings 2092. DOI: http://doi.org/10.1063/1.5096735.

[10] Tuesta, V. A., Alcarazo, F. D., Mejia, H. I., \& Forero, M. G. (2020). Automatic Classification of Citrus Aurantifolia Based on Digital Image Processing and Pattern Recognition. Applications of Digital Image Processing XLIII. DOI: http://doi.org/10.1117/12.2566888.

[11]Huixian, J. (2020). The Analysis of Plants Image Recognition Based on Deep Learning and Artificial Neural Network. IEEE Access, $8, \quad 68828-68841 . \quad$ DOI: http://doi.org/10.1109/access.2020.2986946 .

[12]Feng, X., He, P., Zhang, H., Yin, W., Qian, Y., Cao, P., \& Hu, F. (2019). Rice Seeds Identification Based on Back Propagation Neural Network Model. International Journal of Agricultural and Biological Engineering, 12(6), 122-128. DOI: http://doi.org/10.25165/j.ijabe.20191206.5044

[13] Moham, N., Dwiyanto, F. A., Pakpahan, H. S., Islamiyah, I., \& Setyadi, H. J. (2019). Pengenalan Karakter Tulisan Menggunakan Metode Backpropagation Neural Network. Sains, Aplikasi, Komputasi dan Teknologi Informasi, 1(2), 14. DOI: http://doi.org/10.30872/jsakti.v1i2.2601 .

[14] Gonzalez, R. C. \& Woods, R. E. (2018). Digital Image Processing.4th. Ed. Harlow, Essex. Pearson Education Limited.

[15] Sonka, M., Hlavac, V., Boyle, R. (2015). Image Processing, Analysis, and Machine Vision. 4th Ed. Stamford:CT. Chengage Learning.

[16]Nixon, M. S., Aguado, A. S,. (2002). Feature Extraction and Image Processing, 1st Ed. Woburn, MA. Newnes. 